\author{
Marquette University \\ e-Publications@Marquette
}

9-23-2007

\title{
Diagnosis of Inter-Turn Short Circuit for a Polyphase Induction Motor in Closed-Loop Vector-Controlled Drives
}

\author{
Ahmed Sayed-Ahmed \\ Rockwell Automation \\ Gennadi Y. Sizov \\ Marquette University \\ Nabeel Demerdash \\ Marquette University, nabeel.demerdash@marquette.edu
}

Follow this and additional works at: https://epublications.marquette.edu/electric_fac

Part of the Computer Engineering Commons, and the Electrical and Computer Engineering Commons

\section{Recommended Citation}

Sayed-Ahmed, Ahmed; Sizov, Gennadi Y.; and Demerdash, Nabeel, "Diagnosis of Inter-Turn Short Circuit for a Polyphase Induction Motor in Closed-Loop Vector-Controlled Drives" (2007). Electrical and Computer Engineering Faculty Research and Publications. 506.

https://epublications.marquette.edu/electric_fac/506 


\title{
Marquette University
}

\section{e-Publications@Marquette}

\section{Electrical Engineering Faculty Research and Publications/College of Engineering}

This paper is NOT THE PUBLISHED VERSION; but the author's final, peer-reviewed manuscript. The published version may be accessed by following the link in the citation below.

2007 IEEE Industry Applications Annual Meeting,(October 2007): 2622-2268. DOI. This article is (C) IEEE and permission has been granted for this version to appear in e-Publications@Marquette. IEEE does not grant permission for this article to be further copied/distributed or hosted elsewhere without the express permission from IEEE.

\section{Diagnosis of Inter-Turn Short Circuit for a Polyphase Induction Motor in Closed-Loop Vector-Controlled Drives}

\author{
Ahmed Sayed-Ahmed \\ Department of Electrical and Computer Engineering, Marquette University, Milwaukee WI \\ Gennadi Y. Sizov \\ Department of Electrical and Computer Engineering, Marquette University, Milwaukee WI
}

Nabeel A. O. Demerdash

Department of Electrical and Computer Engineering, Marquette University, Milwaukee WI

\begin{abstract}
The main objective of this paper is to develop and experimentally verify a new technique to detect an inter-turn short circuit in one phase of a stator winding of an induction motor energized from a vector-controlled drive.

This is in order to overcome the fault masking difficulties associated with the concept of depending on the actual magnetic field pendulous oscillation between the conventional voltage and current space vectors with respect to a reference that is unaltered by the compensation action of the drive. This technique is based on the flux pendulous oscillation phenomenon. This flux pendulous oscillation is also described in this paper, this in addition
\end{abstract}


to the magnetic field pendulous oscillation previously addressed in prior publications. The new approach has been verified through experimental results which are represented here.

\section{SECTION I. Introduction}

Induction motor AC drives have been used in numerous applications for more than three decades. This includes both open-loop and closed-loop drives. The former are the simplest form of AC motor-drive systems, and in such case there is no compensation with respect to the applied voltage space-vector which is initiated by the drive's controller. On the other hand, closed-loop drives provide voltage space-vector compensation action through adjustment of the applied voltage space-vector. This action is initiated by the drive to minimize or eliminate the error between the feedback torque and speed signals and the reference signals. Vector-controlled drives constitute a special class of closed-loop drives which control the machine's torque as well as speed. This is in order to obtain optimum motor-load dynamic response. This makes the AC induction motor replicate the traditional DC machine which is known for its precise and simple speed control. Vector-controlled closed-loop drives have been used extensively in numerous applications which require precise torque and speed control. The breakthrough in the field of power electronics enabled AC vector-controlled motor-drive systems to replace dc motor-drive systems in a myriad of applications. Meanwhile, motor and drive fault diagnostics have become a major concern from the industrial point of view, particularly in critical applications where motor-drive failure can be costly, catastrophic or life threatening. This remains the major incentive for a considerable amount of research in the area of motor-drive system fault diagnostics [1] - [2] [3] [4] [5] [6] [7] [8] [9] [10].

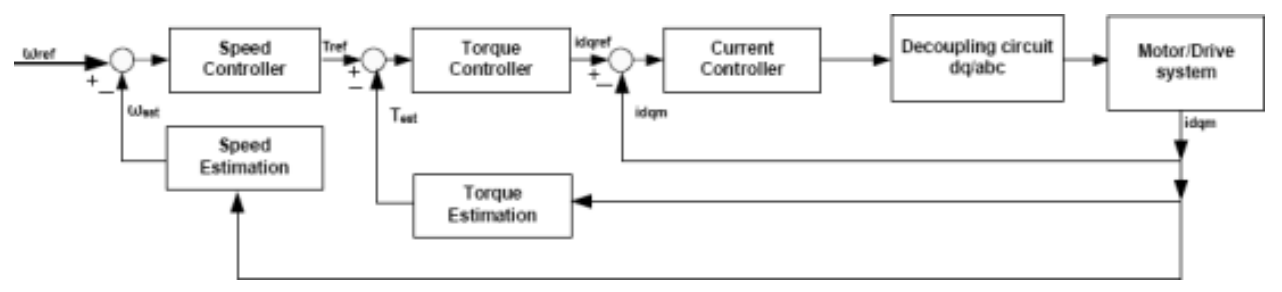

Fig. 1 Simplified block diagram for typical vector-controlled closed-loop drive.

Most of these techniques are only valid for line fed motors or open-loop AC motor-drive systems [1] - [2] [3] [4] [5] [6] [7] [8]. The main objective of this paper is to extend the application of the socalled magnetic field pendulous oscillation phenomenon, which has been introduced and utilized for the diagnosing of inter-turn short circuit faults in open-loop drives and line-fed induction machines in [5], to the case involving closed-loop vector-controlled drives. This paper contains four more sections in addition to this one. The first section analyzes the performance of the closed-loop torque-regulated vector-controlled drive, following the on-set of the early stages of an inter-turn short circuit in a motor in one of the phases of a stator winding. The second section centers upon discussing the new concept of the flux pendulous oscillation (FPO), which utilizes the concept introduced here of a fixed space-vector reference unaffected by the control compensation of the closed-loop drive. The third section demonstrates and explains the experimental results which verify the validity of this new approach presented here in this work. Finally, the fourth and last section discusses and summarizes the work carried out in this research

\section{SECTION II. Analysis of Drive Performance in Case of Stator Winding Inter- Turn Short Circuit Faults}

First, let us consider a healthy three phase induction motor which is controlled using a high performance vectorcontrolled voltage-source inverter (VSI) drive. It is well known that this type of drive utilizes an outer speed control loop for speed control and an inner current control loop in order to regulate the motor torque as shown in Fig. 1. At this point, it should be highlighted that the outlines of the control approach are almost identical in 
these inner and outer control loops. However, the details of the control algorithm might differ from one drive manufacturer to another. The error between a given speed reference and the actual motor speed is processed through the speed controller which outputs a torque reference command to the torque controller. This torque reference command is compared with the actual torque produced by the motor. This motor torque is usually estimated in the drive controller from terminal current and voltage information. The error in the torque is processed through the torque controller which outputs a reference current to the current controller. The output current is processed through the decoupling circuit which is responsible for converting the commanded current to a commanded voltage in which the $d$-axis and q-axis components are decoupled. Subsequently, the $d$-q voltage components are transformed to a stationary abc voltage frame of reference, the abc reference voltage signals are then used to generate the required switching pattern of the inverter switches. The previously described scheme is the backbone of any vector-controlled closed-loop drive, see [11]. According to reference [11], the developed machine torque, $T$ ) which is estimated in the drive can be expressed as follows:

$$
T=(3 / 4) P\left(\vec{\psi}_{s} \times \vec{i}_{s}\right)
$$

where

$$
\vec{\psi}_{s}=\int\left(\vec{v}_{s}-R_{s} \vec{i}_{s}\right) d t
$$

Here, $P$ is the number of poles, $\vec{\psi}_{S}$, is the stator flux space-vector, is, is the stator current space-vector and $R_{S} S$ is the stator phase resistance. This equation can be applied in any reference frame. However, for the sake of our analysis in this paper, a counter clockwise synchronously rotating frame of reference is utilized throughout. One should notice that for a voltage source inverter (VSI) the voltage space-vector is the input to the motor.

Consequently, based on (1) it follows that the stator flux space-vector is also controlled by the action of the drive through its voltage space-vector. Here, the current space-vector and the speed can be considered as the system state variables, while the torque is the system output. Now, let us consider a case of an inter-turn short circuit in one phase in the stator winding. The resultant MMF can be resolved into a counter clockwise (CCW) forward component rotating at synchronous speed and a clockwise (CW) backward field component rotating in the opposite direction, also at synchronous speed, [5]. Consequently, the current space-vector can be resolved into a forward component rotating $\mathrm{CCW}$ at synchronous speed and a backward component rotating $\mathrm{CW}$ at synchronous speed, the resultant current space-vector, $\overrightarrow{i_{s}}$, can therefore be expressed as follows:

$$
\vec{i}_{s}=\vec{i}_{f}+\vec{i}_{b}
$$

where, $\overrightarrow{i_{f}}$, is the forward component of the current space-vector that is produced by the healthy winding, and $\overrightarrow{i_{b}}$, is the backward component of the current space-vector which has resulted from the asymmetry caused by the inter-turn short circuit in the winding of the machine. Hence, the torque for a faulty machine can be expressed by space-vector cross-products as follows:

$$
T=(3 / 4) P \vec{\psi}_{s} \times\left(\overrightarrow{i_{f}}+\overrightarrow{i_{b}}\right)=(3 / 4) P\left(\vec{\psi}_{s} \times \overrightarrow{i_{f}}+\overrightarrow{\psi_{s}} \times \overrightarrow{i_{b}}\right)
$$

The first term in (3) represents a constant (dc) torque component which is produced due to the interaction between the stator flux space-vector and the forward component of the stator current space-vector.

Meanwhile, the second term represents torque oscillations, with a frequency equal to double the fundamental frequency, which is produced due to the interaction between the stator flux space-vector and the backward component of the stator current space-vector. As mentioned before, the voltage space-vector, $\vec{v}_{s}$, is the only 
input to the motor from the VSI-drive, which directly impacts the stator flux space-vector, $\vec{\psi}_{S}$. Thus, it should be expected that the compensation action of the vector-controlled drive, which would minimize these torque ripples, will appear as adjustments to the output voltage space-vector of the drive, $\vec{v}_{s}$. Hence, because of this adjustment, the drive's output voltage space-vector, $\vec{v}_{s}$, can be resolved into a forward, $\vec{v}_{f}$, component and a backward, $\vec{v}_{b}$, component. Consequently, the stator flux space-vector, $\vec{\psi}_{S}$, can also be resolved into a forward and a backward component, $\vec{\psi}_{f}$ and $\vec{\psi}_{b}$, respectively, where,

$$
\vec{\psi}_{s}=\vec{\psi}_{f}+\vec{\psi}_{b}
$$

Accordingly, the torque in (3) can be rewritten to include the compensation action from the drive as follows:

$$
\begin{gathered}
T=\left(3 / 4 \quad \overrightarrow{\psi_{f}}+\vec{\psi}_{b}\right) \times\left(\overrightarrow{i_{f}}+\overrightarrow{i_{b}}\right)= \\
(3 / 4) P\left[\left(\vec{\psi}_{f} \times \overrightarrow{i_{f}}\right)+\left(\vec{\psi}_{f} \times \overrightarrow{i_{b}}\right)+\left(\vec{\psi}_{b} \times \overrightarrow{i_{b}}\right)+\left(\vec{\psi}_{b} \times{\overrightarrow{i_{b}}}\right)\right]
\end{gathered}
$$

It should be noticed that the first term in (5) represents torque produced due to the interaction between the forward component of the stator flux space-vector and the forward component of the stator current spacevector. This term produces a constant $(\mathrm{dc})$ torque component which is the main developed/useful torque in the machine. The second term in (5) represents the torque produced by the interaction between the forward component of the stator flux space-vector and the backward component of the stator current space-vector, this term produces torque ripples (pulsations) with a frequency equal to double the fundamental frequency. The third term represents the interaction between the backward component of the stator flux space-vector and the forward component of the stator current space-vector. This term, again, produces torque ripples with a frequency equal to double the fundamental frequency. The fourth term results from the interaction between the backward component of the stator flux space-vector and the backward component of the stator current space-vector. This term produces a constant (dc) torque component, acting in opposite direction to the main torque produced by the first term in (5). This means that the average developed torque is reduced in the case of an inter-turn short circuit. Now, the drive's controller will try to track the reference torque which will be assumed constant to simplify our analysis. Then, the drive has to increase the torque produced by the interaction between $\vec{\psi}_{f}$ and $\vec{i}_{f}$ to cancel out the torque produced due to the interaction between $\vec{\psi}_{b}$ and $\vec{i}_{b}$. This is achieved by increasing the magnitude of $\vec{\psi}_{f}$ and consequently increasing the forward component of the applied stator voltage space-vector, $\vec{v}_{f}$. Meanwhile, the backward component of the stator flux space-vector, $\vec{\psi}_{b}$, should be adjusted to cancel or mitigate the ac torque ripples produced by the second and the third term in (5) by adjusting the backward component of the applied stator voltage space-vector, $\vec{v}_{b}$ where $\vec{v}_{s}=\vec{v}_{f}+\vec{v}_{b}$. At this stage, one should notice that the compensation action of the drive depends on the tuning status of its controller. The loci of the voltage space-vector, $\vec{v}_{s}$, stator current space-vector, $\vec{i}_{s}$, and the stator flux spacevector, $\psi \vec{S}$ under faulty conditions are depicted in Fig. 2. 


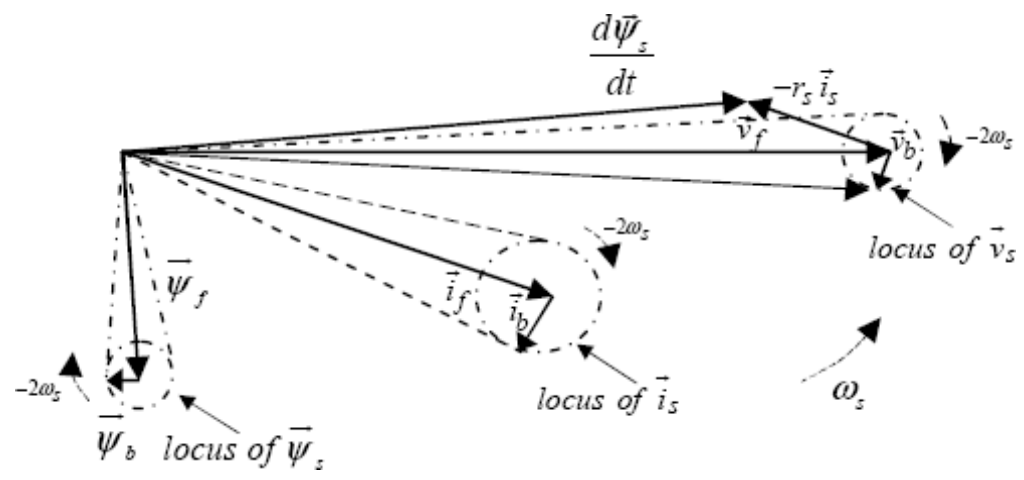

Fig. 2 Space vector diagram of vector-controlled motor-drive system for a case of inter-turn short circuit in one of the stator winding fault ( $\omega_{s}$ is the synchronous speed)

\section{SECTION III. The Concept of the Flux Pendulous Oscillation}

The concept of the magnetic field pendulous oscillation (MFPO) has been previously presented in several publications [5], [6]. This MFPO phenomenon can best be defined as the fluctuation of speed of rotation of the resultant magnetic field with respect to a synchronously rotating frame of reference, due to asymmetry either in the stator and/or the rotor circuits, which also produces torque ripples that might degrade system performance. These oscillations in the resultant rotational magnetic field are measured with respect to the synchronously rotating voltage space-vector as a reference. However, for a closed-loop motor-drive system, which has a well tuned torque regulator, the drive controller tries to compensate for these torque ripples by modulating the applied stator voltage space-vector at the motor terminals. Consequently, for this case, the voltage space-vector and hence the resultant rotational magnetic field (flux) space-vector, also fluctuate with respect to a CCW synchronously rotating frame of reference in order to alleviate the torque ripples which are produced as a result of the fault. Hence, in such a case, the oscillations in the stator current space-vector and the flux space-vector can be monitored separately using a reference frame produced by a phase locked loop (PLL). Although, the PLL concept has been explained in detail in several publications [12] - [13] [14], it will be briefly summarized here for the sake of continuity and reader's convenience. A simplified block diagram for the PLL concept is depicted in Fig. 3, [12].

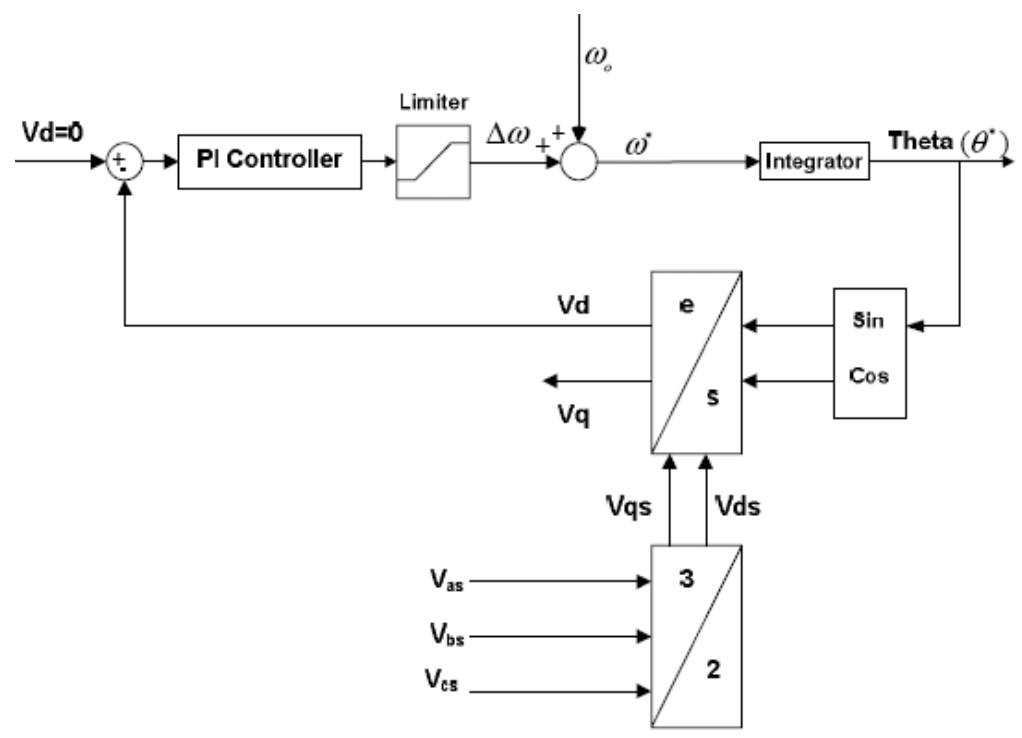

Fig. 3 Simplified block diagram for the phase locked loop 
The drive's output line voltages, $v_{a b}, v_{b c}$, and $v_{c a}$, are measured and then transformed from the abc stationary reference frame to a synchronously rotating $\mathrm{d}$-q reference frame leading to the voltage components, $v_{d}$ and $v_{q}$. This rotating $\mathrm{d}$-q frame is synchronized to the output frequency of the drive. The angle theta, $\theta^{*}$, in Fig. 3 which is used in this transformation, is obtained by integrating an angular frequency command, $\omega^{*}$. In this reference frame, $v_{d}$ and $v_{q}$, appear as dc components depending on the angle, $\theta^{*}$. The PI controller is used to obtain that value of $\omega^{*}$ (or $\theta^{*}$ ) to render the transformed feedback voltage component, $v_{d}$, to a value equal to a zero. At this point, it should be mentioned that the angle, $\theta^{*}$, is not affected by any oscillation which might be produced as a result of a faulty condition. Accordingly, the angle, $\theta^{*}$, can be used as a reference, which is $\mathrm{CCW}$ rotating with a speed equal to the synchronous speed. Now, for closed-loop drives, the new concept of "Flux Pendulous Oscillation" (FPO) can be defined as the oscillation of the stator voltage space-vector with respect to the angle, $\theta^{*}$. Also, here the aforementioned MFPO can be measured as the oscillation of the stator current space-vector with respect to the angle, $\theta^{*}$, which is generated by the PLL algorithm. The diagnostic technique introduced here employs two PLLs running concurrently. One is dedicated to measuring the oscillation of the current space-vector, PLLi while the other is dedicated to measuring the oscillation in the voltage space-vector, $P L L v$ Consequently, the flux space-vector traces a locus as shown in the space-vector diagram of Fig. 4. In this technique, the instantaneous oscillation in the current space-vector, $i_{s}$, with respect to the output angle of the PLLi, $\theta_{\text {iref }}$, and the instantaneous oscillation in the voltage space-vector, $\vec{v}_{s}$, with respect to the output angle of the PLLv, $\theta_{v r e f}$ are continuously monitored. It should also be noticed that the difference between the output angle of the PLLv, $\theta_{v r e f}$, and the output angle of the PLLi, $\theta_{\text {iref }}$, is the machine's power factor angle. Accordingly, this algorithm can also be used to monitor the machine power factor angle.

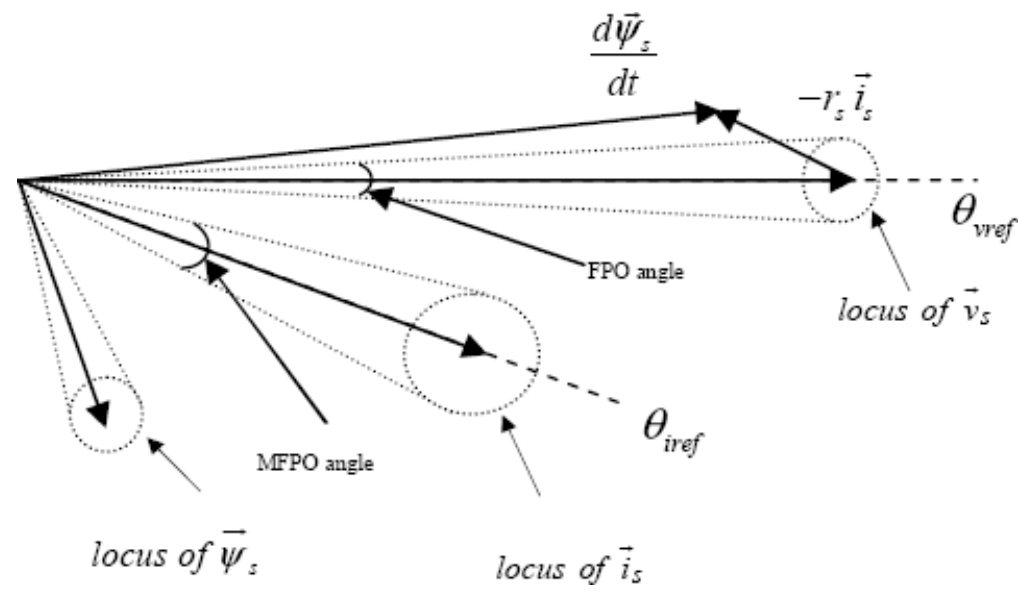

Fig. 4 Space vector diagram of vector-controlled motor-drive system illustrates the concept of the flux pendulous oscillation FPO and the magnetic field pendulous oscillation MFPO

\section{SECTION IV. Experimental Results and Discussion}

In this section, the analysis and concepts presented in the previous sections are experimentally verified and explained through several motor-drive system tests. The experimental setup consists of a 5-hp, 460-Volt, 6-pole, 3-phase induction motor, in which one of its phases has been rewound to enable the investigator to emulate an inter-turn short circuit, see the schematic winding diagram of Fig. 5, and the experimental setup's functional block diagram and physical components as depicted in Fig. 6 . This motor was energized from a commercially available closed-loop drive. This drive can be programmed to run in either a closed-loop vector-control mode or open-loop mode. The voltage and current waveforms were collected using a data acquisition system, see Fig. 6, with a sampling frequency of $50 \mathrm{kHz}$. Notice that the faulty loop (shorted turns loop) current, $i_{f}$, shown in Fig. 5, is one of the parameters being monitored in the test results given below. 


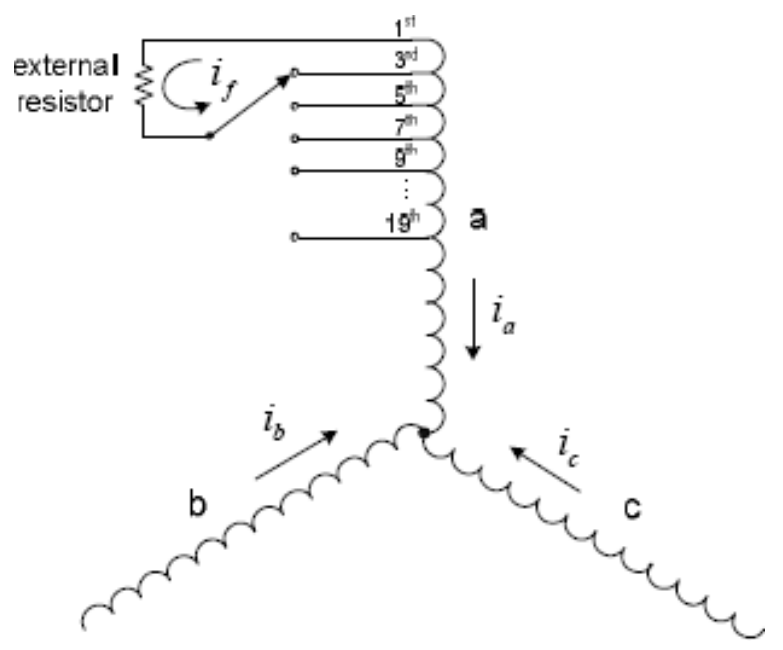

Fig. 5 Schematic diagram of stator windings with taps

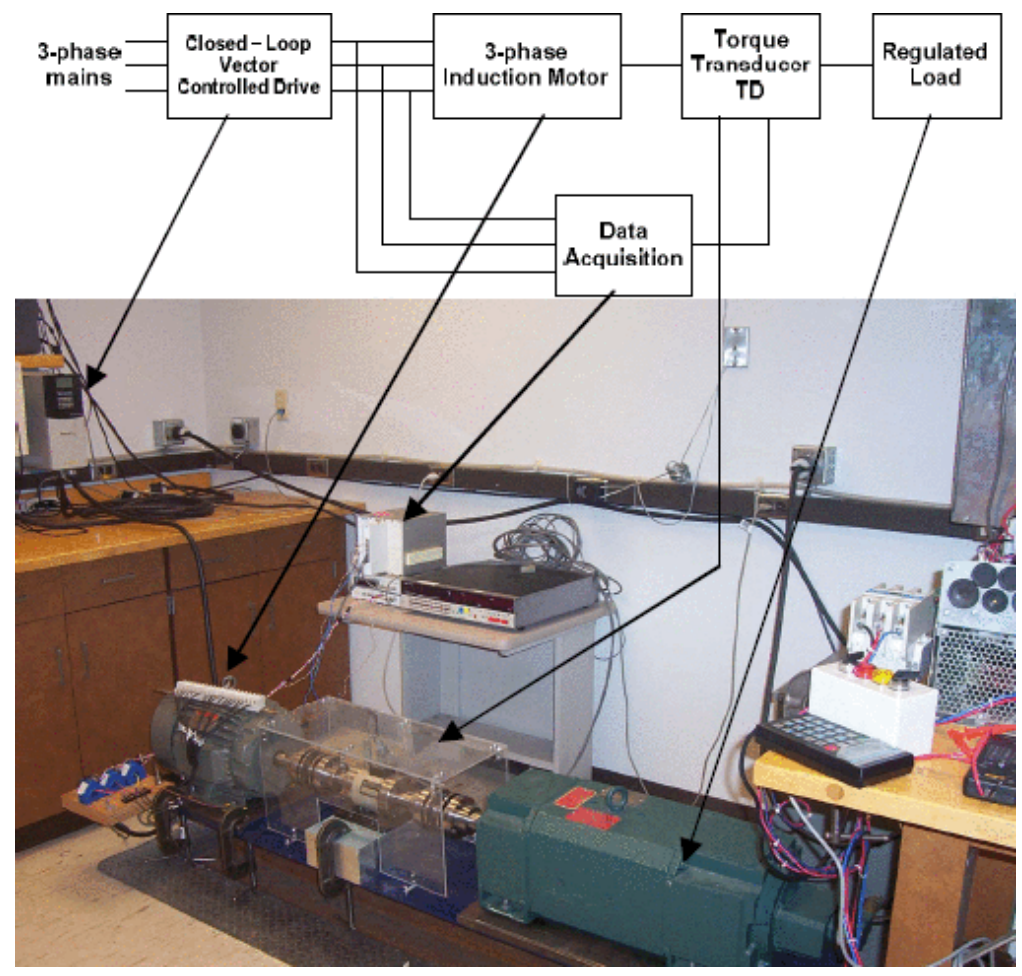

Fig. 6 Experimental set up and its associated function block diagram

The data has been collected and processed using a Matlab-Simulink program, a self-explanatory flow chart for the diagnostic algorithm subject of this paper is depicted in Fig. 7. The main features of this algorithm are the generation of the resultant stator flux space-vector pendulous oscillation (FPO) angle, $\delta_{\mathrm{v}}$, and the stator current space-vector pendulous oscillation (MFPO) angle, $\delta_{i}$.

A set of experimental tests has been carried out using the previously explained experimental setup to verify the validity of the concepts presented in this paper. Here, with the drive operating in its closed-loop mode, the results in Fig. 8 show the variation in the resultant flux's space-vector pendulous oscillation (FPO) angle (stator voltage space-vector), $\delta_{\mathrm{v}}$, and the stator current space-vector pendulous oscillation (MFPO) angle, $\delta_{i}$, for a full- 
load torque condition of $30 \mathrm{Nm}$, versus the magnitude in per unit of the faulty loop circulating current, $i_{f}$ see Fig. 5. It can be noticed that the FPO angle increases with respect to the faulty loop current while the MFPO angle almost experiences no change with respect to that current. This is due to the compensation action of the closeloop drive's controller, which is in line with the theoretical concepts previously elaborated-on in Section II above. The data in Fig. 9 shows the corresponding results for the half-load condition of $15 \mathrm{Nm}$. It can be noticed that the percentage increase in the FPO angle, $\delta_{\mathrm{v}}$, with respect to the faulty-loop circulating current, $i_{f}$ for the case of full-load $(30 \mathrm{Nm})$ is higher than that for the halt-load $(15 \mathrm{Nm})$ condition. Meanwhile, the variation of the MFPO angle, $\delta_{i}$, versus the faulty-loop circulating current for a half-load condition $(15 \mathrm{Nm})$ is higher than that for a fullload condition.

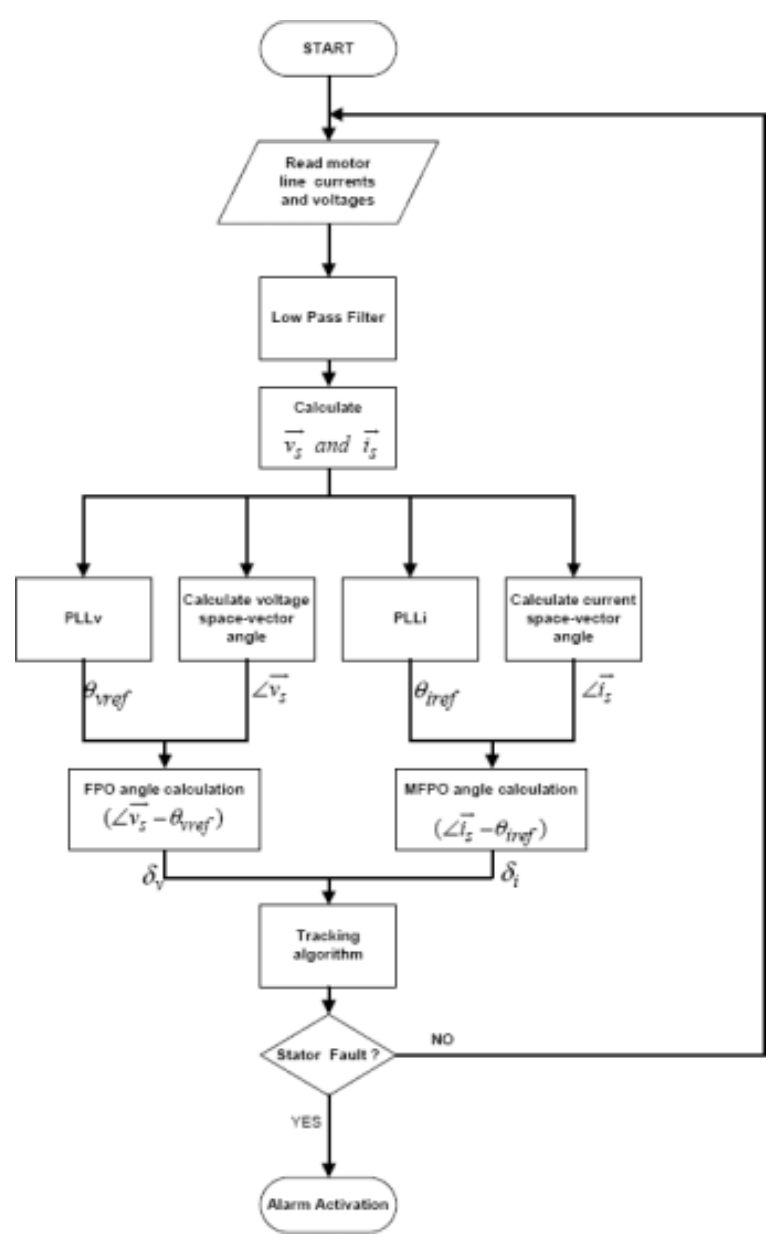

Fig. 7 Flow chart for the diagnostic algorithm

This can be attributed to the closed-loop drive controller's response to the torque ripples developed as a result of the fault. This can also be attributed largely to the fact that the drive controller was tuned for optimum compensation at the full-load condition and consequently less so (sub-optimally) at half-load condition. Meanwhile, Fig. 10 shows a considerable increase in the magnitude of the applied stator voltage space-vector with respect to the faulty loop current when $i_{f} \geq 0.6 p$. $u$ for both cases of full-load and half-load conditions. This increase can be attributed to the drive controller's response to the negative torque produced by the interaction of the backward component of the stator flux space-vector and the backward component of the current space-vector as pointed out earlier in discussing the fourth term in (5).

It was also interesting to monitor the variation of the summation of the stator current space-vector pendulous oscillation (MFPO) angle, $\delta_{i}$, and the resultant flux's space-vector pendulous oscillation (FPO) angle (stator 
voltage space-vector), $\delta_{\mathrm{v}}$, which are depicted in Fig. 11 at full-load and half-load conditions. It can be noticed that the summation of $\delta_{\mathrm{v}}$ and $\delta_{i}$ is increasing monotonically with respect to the faulty loop current, $i_{f}$ which makes this summation $\left(\delta_{i}+\delta_{v}\right)$ a very effective diagnostic index. The rate of increase of this index can be used as an indication of the deterioration of the fault condition.

Meanwhile, Fig. 12 demonstrates the variation of the MFPO angle, $\delta_{i}$, and FPO angle, $\delta_{\mathrm{v}}$, with respect to the faulty-loop circulating current, $i_{f}$ for the case of the open-loop operating mode of the drive, in which the drive's controller compensation action does not exist. Here, one should observe the dramatic increase in the value of the MFPO angle, $\delta_{i}$, versus the faulty-loop circulating current, $i_{f}$. In this case, it should be noticed that there is almost no change in the FPO angle, $\delta_{\mathrm{v}}$, which was naturally expected for the open-loop mode of operation of this drive. This is because under this mode there is no controller compensation action with regard to the voltage space-vector, $\vec{v}_{s}$.

Based on the previous discussion and the experimental results, a new diagnostic approach is introduced in this work. The new diagnostic approach depends on monitoring the increase in both the MFPO angle and the FPO angle for the purpose of diagnosing of inter-turn short circuit fault when a motor is energized from a vectorcontrolled closed-loop drive. It is also recommended that one should monitor the machine's developed airgap torque through use of a suitable torque observer based on using only terminal voltages and currents, [11]. In summary, in case of motor operation using vector-controlled closed-loop drives, for an inter-turn fault condition at full-load, a considerable increase in the FPO angle, $\delta_{\mathrm{v}}$, was expected and experimentally verified without any corresponding considerable change in the MFPO angle, $\delta_{i}$. Meanwhile, for any light load condition, an increase in the MFPO angle and the FPO angle is noticed because the drive's tuning was most likely optimally set for fullload operation. The above mentioned technique may be enhanced by means of applying a set of fuzzy rules for decision making which will be addressed by the authors in future work.

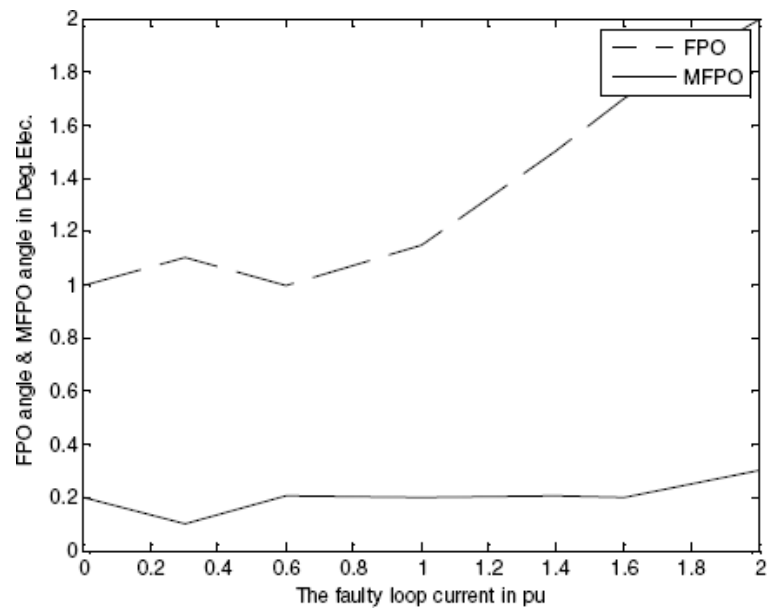

Fig. 8 FPO angle and MFPO angle versus the faulty loop current, $i_{f}$ for closed-loop drives at full-load conditions 


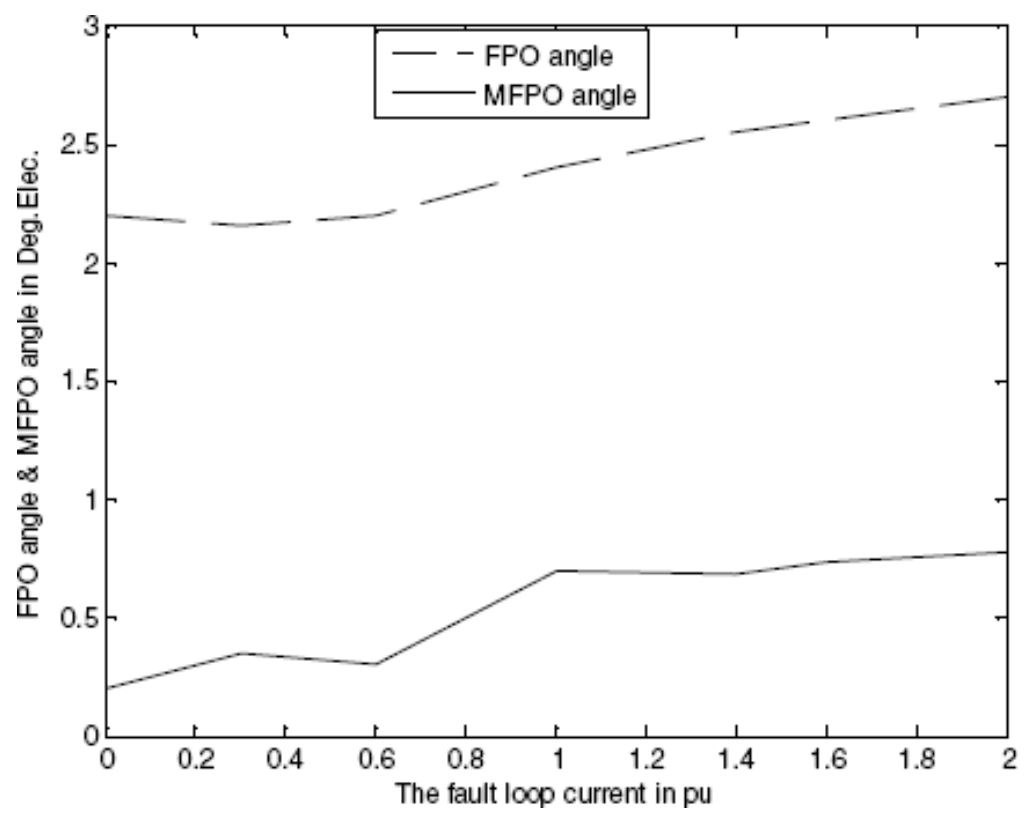

Fig. 9 FPO angle and MFPO angle versus the faulty loop current, $i_{f}$ for closed-loop drives at half-load conditions

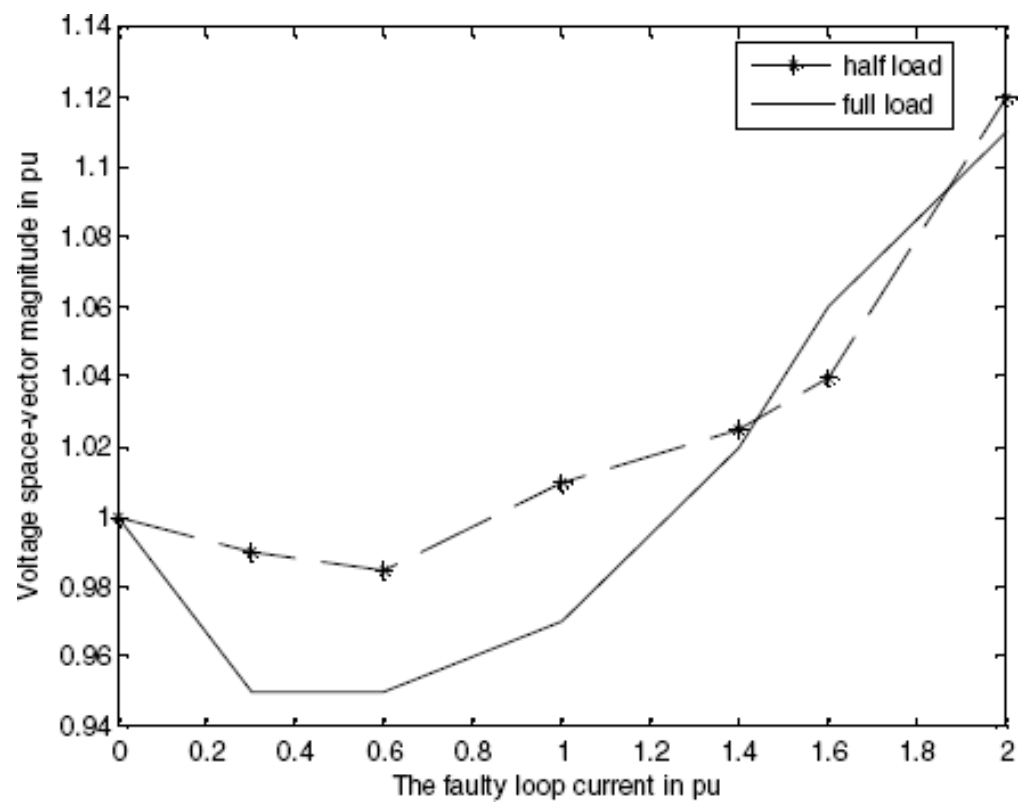

Fig. 10 Magnitude of the voltage space-vector versus the faulty loop current, $i_{f}$ for closed-loop drives at halfload and full-load conditions 


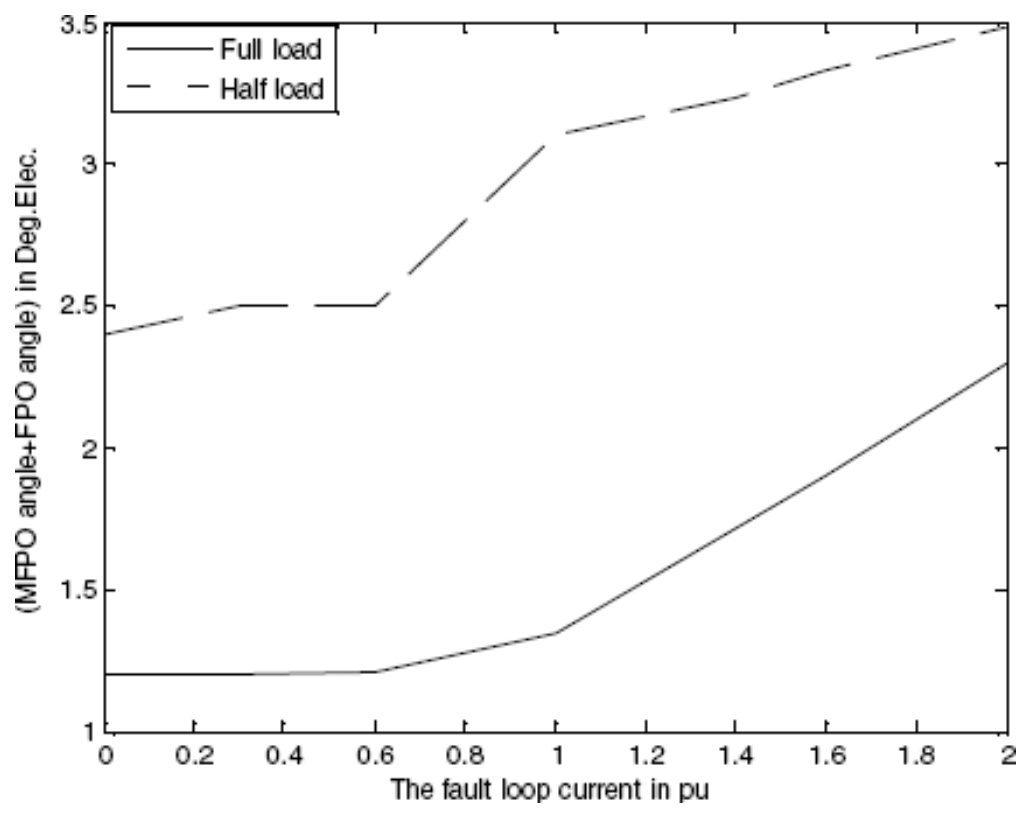

Fig. 11 (FPO angle + MFPO angle) versus the faulty loop current, $i_{f}$ for closed-loop drive at both half load and full load conditions

\section{SECTION V. Conclusion}

This paper introduces a new technique to detect inter-turn short circuit faults in one phase of a motor's stator winding supplied by vector-controlled closed-loop drives used in high performance motor-drive applications. The technique utilizes the phase locked loop (PLL) concept to track the angles of the voltage and current spacevectors. These angles were found to be indicative of the severity of the circulating faulty loop current, and hence the severity of the fault. The paper also introduces the new concept of the stator flux pendulous oscillation which has been found by these authors to be influenced by the compensation action initiated by the drive, in its effort to alleviate or mitigate the torque ripples produced due the shorted-turn fault conditions. Although the technique was verified through offline tests, the authors' judgment is that it can be readily implemented in a DSP board of a drive. The technique was verified through a set of experimental results carried out at various load conditions.

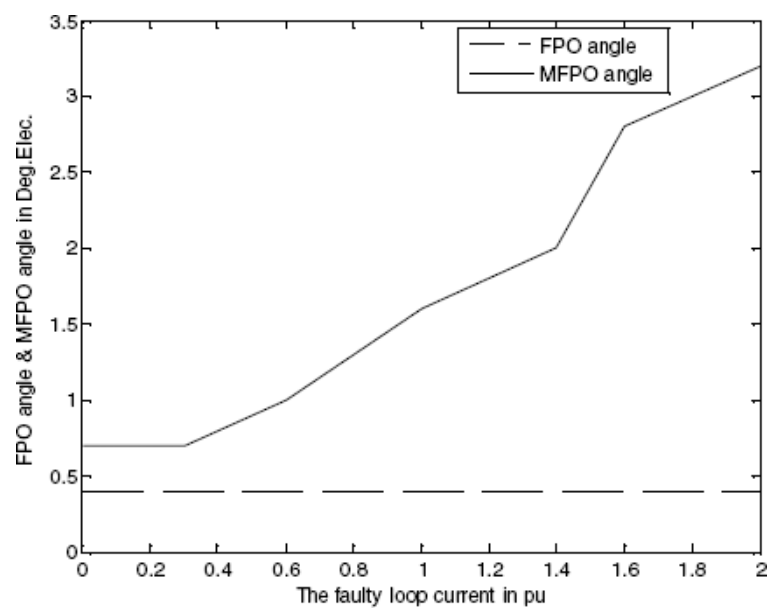

Fig. $12 \mathrm{FPO}$ angle and MFPO angle versus the faulty loop current, $i_{f}$ for open-loop drives at full-load conditions 


\section{ACKNOWLEDGMENT}

Authors wish to acknowledge the support of Mr. Richard A. Lukaszewski, Mr. Kenneth P. Phillips, and Mr. Jon W. Simons of Rockwell Automation/Allen-Bradley in providing the hardware equipment without which these experiments could not have been possible. This work was also partially supported by NSF grant Numbers ECS0322974 and OISE-0609731

\section{References}

1. A. Stavrou, H.G. Sedding, and J. Penman "Current Monitoring for Detecting Inter-Turn Short Circuits in Induction Motors," IEEE Trans. On Energy Conversion, vol. 16, March 2001.

2. J. Penman, H.G. Sedding B.A. Lloyd, and W.T. Fink "Detection and Location of Interturn Short Circuits in the Stator Winding of Operating Motors," IEEE Trans. On Energy Conversion, vol. 9, pp. 652-658, Dec. 1994.

3. G.M. Joksimovic and J. Penman "The Detection of Interturn Short Circuits in the Stator Windings of Operating Motors," IEEE Trans. On Industrial Electronics, vol. 47, Oct. 2000.

4. S. Nandi, H.A. Toliyat, and X. Li "Condition Monitoring and Fault Diagnosis of Electrical Motors-A Review," IEEE Trans. On Energy Conversion, vol. 20, pp. 719-729, Dec. 2005.

5. B. Mirafzal and N.A.O. Demerdash, "On Innovative Methods of Induction Motor Inter-Turn and Broken-Bar Fault Diagnostics" IEEE Trans. On Industrial Applications, vol. 42, No. 2, pp. 405-414, March/April, 2006.

6. B. Mirafzal, R.J. Povinelli, and N.A.O. Demerdash, "Inter-Turn Fault Diagnosis in Induction Motors Using the Pendulous Oscillation Phenomenon," IEEE Transactions on Energy Conversion, vol. 21, Issue 4, Dec 2006.

7. A. Siddique, G.S. Yadava, B.A. Singh, "Review of Stator Fault Monitoring Techniques of Induction Motors," IEEE Transactions on Energy Conversion, vol. 20, pp. 106-114, March 2005.

8. G. Stone, J. Kapler, "Stator Winding Monitoring," IEEE Industry Applications Magazine, vol. 4, pp. 15-20, September/October 1998.

9. Sergio M.A. Cruz, A.J. Marques Cardoso "Diagnosis of Stator Inter-Turn Short Circuits in DTC Induction Motor Drives" IEEE Trans. On Industrial Applications, vol. 40, No. 5 Sept/Oct 2004.

10. Rangarajan M. Tallam, Thomas G. Habetler, and Ronald G. Harley, "Stator Winding Turn-Fault Detection for Closed-Loop Induction Motor Drives" IEEE Trans. On Industrial Applications, vol. 39, No.3 May/June 2003.

11. Peter Vas, "Sensorless Vector and Direct Torque Control", Oxford University press.

12. Licia Neto Arruda, Sidelmo Magalhães Silva, Braz J. Cardoso Filho "PLL Structures for Utility Connected Systems" Industry Applications Conference, 2001. Thirty-Sixth IAS Annual Meeting. Conference Record of the 2001 IEEE.

13. Vikram Kaura, and Vladimir Blasko "Operation of a Phase Locked Loop System Under Distorted Utility Grid" IEEE Trans. On Industrial Applications, vol. 33, No. 1 Jan/Feb 1997.

14. Guan-Chyun Hsieh, and James C. Hung "Phase-Locked Loop Techniques-A Survey" IEEE Trans. On Industrial Electronics, vol. 43, No. 6 Dec. 1996.

\section{Keywords}

\section{IEEE Keywords}

Induction motors, Torque control, Circuit faults, Voltage , Stator windings, Control systems, Velocity control , AC motors , Drives, Magnetic fields

INSPEC: Controlled Indexing

closed loop systems, induction motor drives, machine vector control, short-circuit currents

\section{INSPEC: Non-Controlled Indexing}

inter-turn short circuit, polyphase induction motor, closed-loop vector-controlled drives, stator winding , magnetic field pendulous oscillation, compensation action 